\title{
Can the EU Buy Public Support?
}

\author{
Julian Schuessler*
}

November 19, 2019

\begin{abstract}
The European Union targets up to a quarter of its budget towards underdeveloped regions. Do these investments have an impact on citizens' attitudes towards the EU? The previous literature on this question is scarce and inconclusive. I use a regressiondiscontinuity design to tackle this question. The analysis is based on a large dataset of geocoded individual-level survey responses from every member state that spans more than twenty years. Point estimates for the effect of the funds on public opinion are relatively small and statistically insignificant. Large effects can be ruled out. At the same time, I show that pre-existing attitudes towards European integration correlate with the EU's allocation decisions. Finally, I show that the funds do not have an impact on EU-related attitudes due to informational problems and explore whether the EU's activities may be misattributed to national political actors.
\end{abstract}

*PhD Student, Graduate School of Decision Sciences, University of Konstanz, Germany julian. schuessler@uni-konstanz.de). This project owes much to the invaluable input of Peter Selb, whom I would like to thank. I would also like to thank Elias Dinas, Julia Goehringer, Sebastian Hellmeyer, Max Heermann, Philipp Lutscher, Anselm Hager, Gerald Schneider, Maurizio Strazzeri, Philipp Trein, and seminar participants at the University of Konstanz and EPSA 2017 for helpful comments. Financial support by the Graduate School of Decision Sciences and the German Academic Scholarship Foundation is acknowledged. 


\section{Introduction}

Nation-states as well as supra- and international organizations use monetary transfers for various economic and political reasons. The European Union transfers about a quarter of its budget into investment projects in its poorer regions. As the European project is criticized more and more, the question of whether these transfers make a difference in political terms is pressing. Since the financial crisis of 2007, cleavages between richer and poorer member states have increased. Skepticism towards the project of European integration has realized itself in various political decisions, such as the Brexit referendum in 2016.

It has long been suspected that member states of the EU engage in side-payments to gather support for integration from Eurosceptic nations (Carrubba, 1997). Additionally, knowing the effects of existing EU fiscal policy on citizens' attitudes could inform the lively debate about its extension (Bargain et al., 2013). However, at the regional and individual levels, the empirical evidence for positive effects of such payments on support for the EU is scarce. Existing research mostly ignores the inherently regional nature of the payments, is limited to single snapshots in time, and does not discuss the political mechanisms by which these funds are assigned (Chalmers and Dellmuth, 2015; Hooghe and Marks, 2005). This is especially problematic since it is very likely that politicians distribute funds based on political motives and the pre-existing attitudes of districts or regions. This makes getting at the causal effect of these payments non-trivial (Brollo and Nannicini, 2012).

In this research note, I address these shortcomings. I estimate the effect of the most important regional EU transfers, the "Structural Funds", on individual attitudes towards the union. I exploit the fact that these payments are mostly assigned based on whether a particular region's GDP is below a certain threshold. This discontinuity has already been used to identify the impacts of the payments on regional economies (Becker et al., 2010), but it has not been applied to genuinely political outcomes. In fact, this article is one of the first to use a "natural experiment" to study the causes of public opinion on the EU I I use

\footnotetext{
${ }^{1}$ Foos and Bischof 2018 is another recent exception.
} 
individual-level surveys from the Eurobarometer data set which cover every member state and span the period 1989-2013 is used. This also overcomes the limited coverage in time and space of existing studies.

A unique aspect of this data set, which has not been noted before, is that it is funded by the EU Commission, which also decides which regions are eligible for the funds. Therefore, these data may be used to target specific regions for political reasons. Indeed, I show that pre-existing attitudes towards the EU correlate with funding decisions. This resolves a puzzle in the existing research on the determinants of these funds Bodenstein and Kemmerling, 2011).

My main results indicate that the funds do not affect individual support for a nation's membership in the EU. Point estimates are relatively small and insignificant and exhibit little heterogeneity across time, space, various subgroups, and are robust against potential spillovers. Further analyses suggest that the funds also do not impact citizens' awareness of the policy. Accordingly, it is possible that when evaluating the EU, individuals do not engage in "blind retrospection" (Achen and Bartels, 2016), and that limited communication of the EU's activities undermined their effect.

The empirical analysis concludes by looking into unintended consequences of the EU funds. I find little evidence that they positively affect retrospective evaluations of the national economy and intentions to vote for the national incumbent.

\section{The EU Regional Policy}

Up to 80 percent of the (multi-annual) EU budget consists of the "Common Agricultural Policy" (i.e., transfers to the farming sector) and the "Regional Policy" (i.e., transfers targeted towards specific regions). The latter policy regime started in 1989; the next spending periods were 1994-1999, 2000-2006, and 2007-2013. The geographical unit used for the allocation of funds is based on the official Eurostat "NUTS" [2 system. For most countries, funds

\footnotetext{
${ }^{2}$ Nomenclature des Unités Territoriales Statistique.
} 
were allocated to "NUTS 2" regions.

The EU has spent billions of Euros every year through this mechanism. For example, in the 2007-2013 period, spending was about 230 billion Euros (European Commission, 2016, 10). To put this number into perspective, the total EU budget in this period was about 860 billion Euros. Accordingly, over a quarter of the whole budget was transferred to the poorest regions of the EU $3^{3}$ This underlines how central these funds are to the active spending efforts of the EU.

The policy aims to be comprehensive. Money is not only invested in physical infrastructure (especially transportation) but also projects involving human capital formation, private research and development, environmental projects, and cultural projects. The EU never funds entire projects. Instead, the investments are always co-financed by regional governments, national governments, or private companies.

The EU's poorest regions receive a disproportionate share of funding. Specifically, Regulation 2052/88, article 8, of the Council of the European Union describes the assignment mechanism for this funding scheme as follows:

The regions concerned $[\ldots]$ shall be regions $[\ldots]$ whose per capita GDP [...] is less than 75 percent of the Community average. They shall also include [...] other regions whose per capita GDP is close to that of the regions referred [...] and which have to be included [...] for special reasons.

This legal setup gives rise to a (fuzzy) regression-discontinuity (RD) design. Existing studies (Hooghe and Marks, 2005; Chalmers and Dellmuth, 2015) have disregarded this assignment mechanism behind the EU funds. This poses a significant problem as regional GDP and associated socio-economic background variables also impact attitudes towards the EU independently of the funds. In addition to the presence of this confounding problem, the discontinuity of fund payments as a function of regional GDP makes it difficult, if not

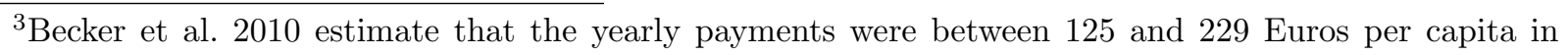
affected regions.
} 
impossible, to achieve overlap if one were to condition on GDP in a regression model. The RDD analysis used in this paper overcomes these problems.

Knowing the exact institutional mechanism behind the funds is useful for understanding issues of identification. The Commission unilaterally decides which regions are part of the program and determines the overall amount of funds available for each member state. The member states then propose specific investment projects and associated costs. These are then reviewed by the Commission with regards to their fit to the general aims of the policy (Council Regulation 2052/88, Article 8). The relevant paragraphs for the proposal and review procedure are vague, so member states and commission have large discretion.

\section{Theoretical Considerations and Relationship to the Existing Literature}

In the EU public opinion literature, three theoretical approaches - utilitarian, identity-based, and "cue-taking" frameworks - emphasize different mechanisms of how people judge the EU (Hobolt and de Vries, 2016, 420). The utilitarian approach, which centers on individual economic benefits, suggests that the funds could plausibly influence attitudes towards the EU through economic channels. This might work under a model of behavior where citizens consciously gather information to assess the benefits from the EU or if citizens engage in "blind retrospection" (Achen and Bartels, 2016). That is, citizens need not necessarily be aware that the source of increased growth is the European Union. If, when asked about their opinion, citizens simply assess the relative development of their (personal or regional) economic situation, the fund payments would have a positive effect solely through their effect on GDP. However, the economic literature does not find effects of the fund payments on employment (Becker et al., 2010) — an issue more salient for most citizens.

The "cue-taking" approach emphasizes that citizens rely on national political actors to form their opinion of the EU. In the case of EU funds, this is true in a very literal fashion 
as member states have the sole duty to inform the public about projects financed by the EU and the source of its funding. Since member states have little incentives to "cue" the EU commission and its funds in a positive light, a positive effect on attitudes may not be activated.

The data used in this paper allow light to be shed on these different mechanisms. First, I estimate whether the EU funds affect citizens' awareness of this policy. Second, I investigate whether they affect retrospective economic evaluations. If the funds affect EU opinion, then looking into these channels informs us whether this is grounded in a cognitive process that consciously connects funds and judgments of the EU or in blind retrospection.

Concerning specific analyses of the opinion effects of EU payments, existing research is limited in multiple ways. Hooghe and Marks (2005) analyze a single Eurobarometer survey and include a dummy variable that indicates whether a respondent's country (not: region) receives net benefits from the EU. A similar approach is chosen by Karp et al. (2003). This seems to be a somewhat crude measure which is probably not informative. Chalmers and Dellmuth (2015) and Dellmuth and Chalmers (2018) analyze Eurobarometer surveys for a sub-sample of member states using regional transfer measures as the explanatory variable. However, it is unclear whether their generally positive effect estimates on support for the EU are credible. They do not discuss the legal and political procedures by which transfers are assigned. Specifically, they do not seem to be aware of the 75 percent threshold rule and do not adjust for regional GDP.4 The research project by Borz et al. (2018) as well as the analysis of the effect on subnational party positions by Gross and Debus (2018) suffers from the same problems. Therefore, the present study constitutes a significant step forward in understanding the effects of the EU funds. This is accomplished by using a credible design and covering every member state over an extended period.

Another strand of the literature looks into the determinants of EU funds but has paid almost no attention to regional support as a determinant of EU fiscal policy (Bouvet and \begin{tabular}{l}
\hline${ }^{4}$ In fact, Dellmuth and Chalmers $(2018,9)$ acknowledge that EU officials might spend funds strategically \\
to increase public support, but do not explicate how they solve this problem.
\end{tabular} 
Dall'Erba, 2010; Bodenstein and Kemmerling, 2011; Charron, 2016). Similarly, Becker et al. (2010, Figure 4) scrutinize whether a range of economic variables influences the decision to fund certain regions, but do not find any evidence. The Eurobarometer data are uniquely suited for tracing the EU Commission's decision-making process. Therefore, my study also adds to this literature. Finally, the literature on foreign aid suggests that it may be misattributed to domestic politicians that are not formally involved in the decision-making (Cruz and Schneider, 2017). Here, I explore this issue in the context of the European Union.

\section{Data and Estimation}

To analyze the causes and consequences of the EU funding program, I use Eurobarometer individual-level survey data, merged with information on GDP per capita of the region in which individuals live and whether this region received money from the EU Structural Fund. The latter information is gathered from the relevant Council regulations and Commission documents (Council Regulation No 2052/88, Commission Decisions 1999/502 and 2006/594, and European Commission 1997). Data on regional GDP and population is obtained from Cambridge Econometrics, European Regional Data.

Figure 1 shows all NUTS 2 regions in the EU as of 2018 which received funding at least once in the 1989-2013 period. Most treated regions are in southern and eastern Europe. However, parts of Germany, the UK, Ireland, and Belgium have also received some funding. While almost all regions in eastern Europe received funding after their accession in 2004 and 2007, there was much more intracountry variation in southern Europe, especially in Spain and Italy.

The other main data source is the Eurobarometer survey. It usually asks respondents to state their opinion on the membership of their country in the EU. Possible answers are "Good Thing", "Bad Thing", and "Neither nor". This question is extremely popular for research into the determinants of attitudes towards the EU (Hobolt and de Vries, 2016). To keep 


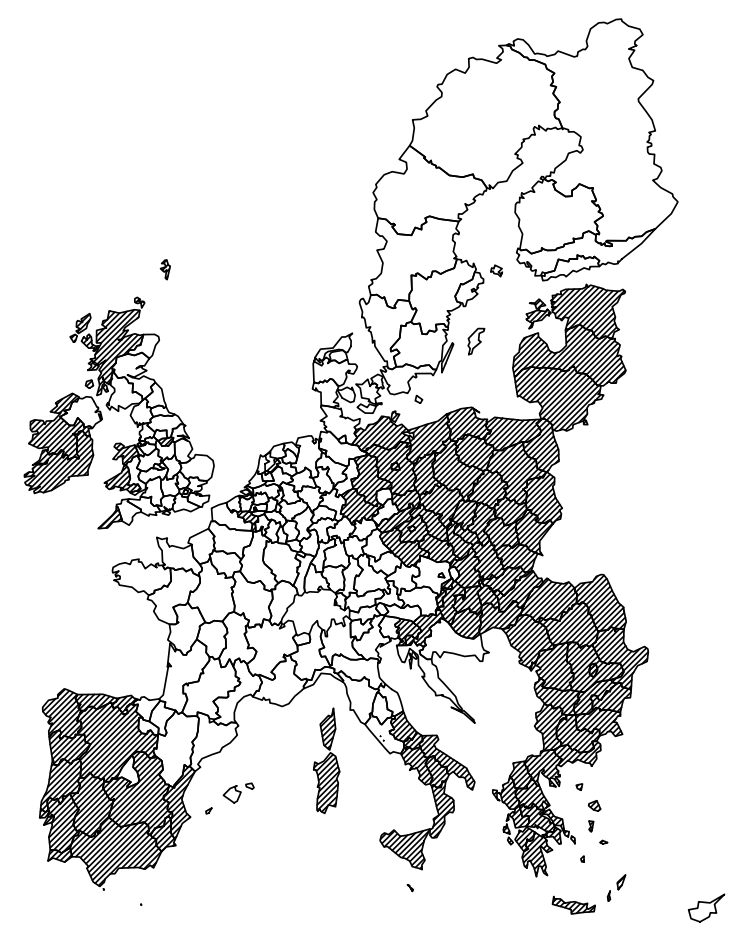

Figure 1. Regions in the EU that received funding at least once

Note: NUTS 2 regions in the European Union. Hatched areas received funding at least once in the 1989-2013 period. Overseas departments and exclaves not shown. Sparsely populated parts of regions in Finland that received special funding are not hatched.

the presentation of results simple, the membership question is recoded into a binary variable indicating whether a respondent stated that membership was a "good thing". Further details on the surveys used can be found in the online appendix.

\subsection{Treatment Effect Estimation}

As argued above, the institutional setup behind the EU funds constitute a fuzzy regressiondiscontinuity design. The main results, therefore, are based on estimating

$$
\frac{\lim _{x \uparrow 0.75} E\left[Y_{r t} \mid X_{r t}=x\right]-\lim _{x \downarrow 0.75} E\left[Y_{r t} \mid X_{r t}\right]}{\lim _{x \uparrow 0.75} E\left[D_{r t} \mid X_{r t}=x\right]-\lim _{x \downarrow 0.75} E\left[D_{r t} \mid X_{r t}\right]} .
$$

Here, $Y_{r t}$ is the region-year specific share of citizens who state that the EU is a "good thing", $X_{r t}$ is a region's GDP per capita as a fraction of the EU average prior to program 
start, and $D_{r t}$ is 1 if a region actually received funds. Further details on the operationalization of the treatment as binary can be found in the online appendix.

A causal interpretation can be given to this estimand under a set of standard assumptions. These resemble an instrumental-variables setup (Choi and Lee, 2018). For this to work, fund eligibility must depend monotonically on regional GDP. This seems plausible under the legal framework. Second, mean potential outcomes $E\left[Y_{r t}(d) \mid X_{r t}\right]$, as well as $E\left[\left(Y_{r t}(1)-\right.\right.$ $\left.\left.Y_{r t}(0)\right) D_{r t}(0) \mid X_{r t}\right]$ and $E\left[D_{r t}(0) \mid X_{r t}\right]$, should be continuous in $X$ at the 75 percent threshold. This is plausible since I am not aware of any other major program utilizing this threshold. Specifically, funding through the EU Cohesion Policy depends on whether a member state (not: region) is below 90 percent of the average Gross National Income, so this poses no threat to identification. These continuity assumptions could be violated if the regions were able to manipulate their GDP to sort into the program and if the variables driving this were related to Euroscepticism (De la Cuesta and Imai, 2016).

My main estimates of equation 1 rely on local linear regressions with heteroscedasticityconsistent estimators for the standard errors (Imbens and Kalyanaraman, 2012; Dimmery, 2016) as well as recent estimators proposed by Calonico et al. (2014, 2015). I use multilevel regression with post-stratification (MRP, Gelman and Little (1997)) to tackle various estimation problems in a unified way. While the relevant unit of observation is the NUTS 2 region-year, the attitudinal data is on the individual level. This means that responses need to be aggregated on the regional level. Additionally, Eurobarometer is not representative of the European population by design, as smaller countries are heavily oversampled, and it suffers from both item and survey nonresponse. MRP can be used to adjust for unequal sampling probabilities and survey nonresponse, while I use multiple imputation to handle missing values. All of these problems are rarely discussed in the empirical literature on EU opinion so that my approach is also fruitful for future research in this area. Further details on this procedure can be found in the online appendix. 


\section{Results}

In the online appendix, I provide evidence for the validity of the design: The first-stage is strong and sorting around the threshold is not a concern. Additionally, I show that prior EU attitudes in regions correlate with treatment assignment, which is an interesting substantive finding that also suggests controlling for prior EU attitudes in the main analysis.

I now present treatment effect estimates that pool all regions and funding periods, and have outcomes measured one to four years after funding start.5 Note that nonparametric bounds on the ATE of the funds on opinion are $[-0.46,0.54]$. These are a useful starting point to interpret the information added by the RDD ${ }^{6}$ Point estimates and 95 percent confidence intervals from the RDD are depicted in Figure 2, Solid lines represent unadjusted estimates, while dashed lines adjust for prior EU attitudes. Point estimates throughout are very close to zero with fairly tight confidence intervals. The unadjusted estimate with an outcome lead of four years is positive and borderline significant at the 10 percent level, but this is not robust to adjustment for past EU attitudes.

A reduced-form plot (Figure A3 in the appendix) of EU attitudes with a four-year lead shows the clearest signs of a positive effect. However, this estimate is also clearly insignificant. In sum, this pooled analysis supports the notion that the funds do not have an effect on EU attitudes for regions at the threshold.

There may be dynamic effects that are masked by a pooled analysis. Figure 3 depicts estimates for each separate year from 1989 to 2013, adjusted for prior attitudes. However, this exercise overwhelmingly points towards zero or extremely small effects. Some estimates are significant, depending on the bandwidth choice, but this is erratic and to be expected given the number of computed significance tests. There is certainly no visible trend in the point estimates that would indicate that the impact of the program slowly unfolds over time 7

\footnotetext{
${ }^{5}$ This is because the first funding period ended after four years.

6 Manski (1990). The RDD targets a local LATE, which could be outside the bounds for the ATE. However, it seems plausible to assume that the LATE too has to lie within these bounds.

${ }^{7}$ Exact estimates can be found in Table A5 in the online appendix.
} 


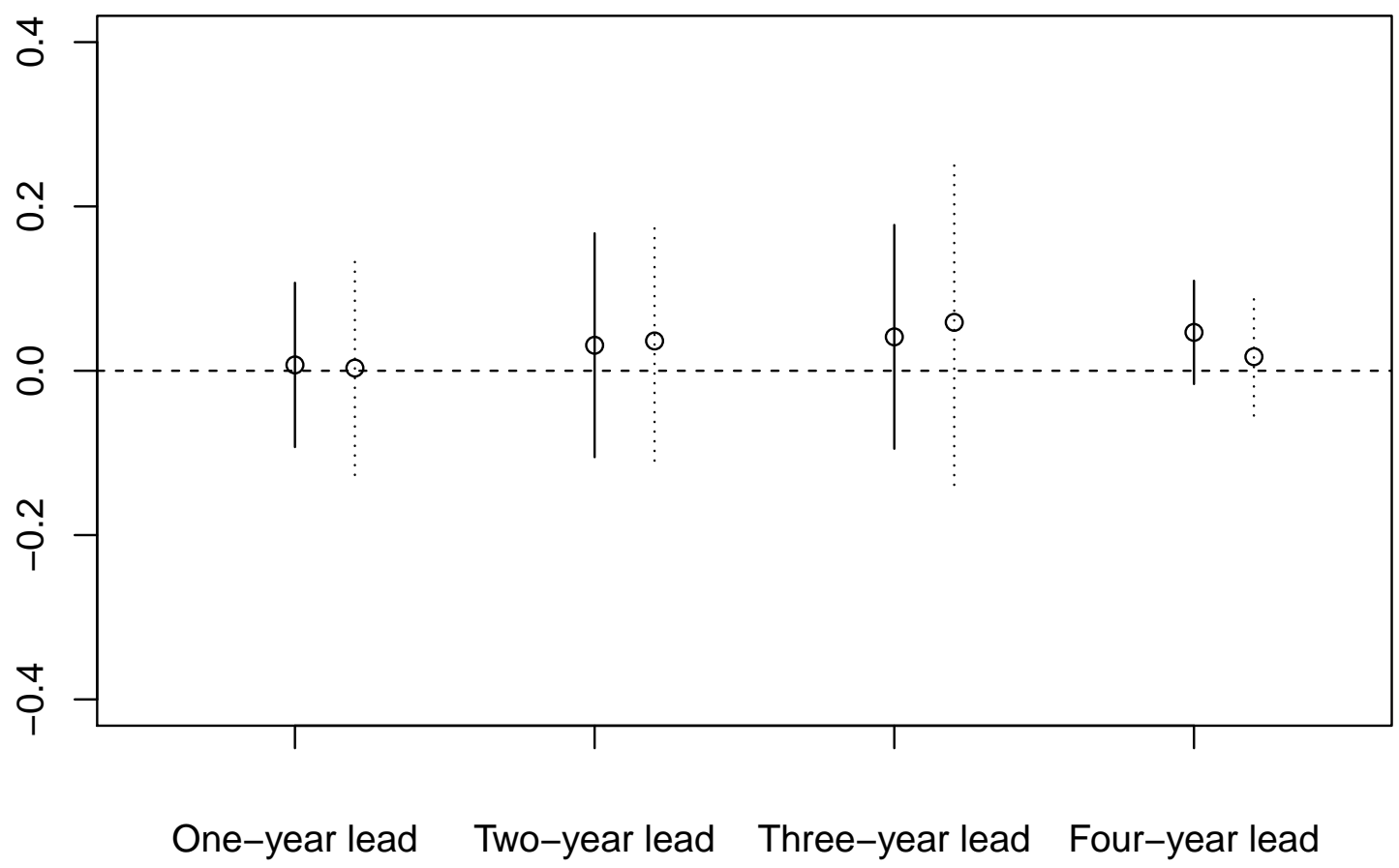

Figure 2. $\quad R D$ estimates of the impact of EU funds on attitudes towards the $E U$

Note: 95 percent confidence intervals based on local linear regressions with Imbens-Kalyanaraman bandwidths and a heteroscedasticity-consistent estimator of the standard errors. Bold lines are unadjusted, while dotted lines are based on an estimator that adjusts for past EU opinion. Outcomes are measured one to four years after the start of program participation. Based on pooled data that includes all regions in the 1989, 1994, 2000, and 2007 funding periods.

Table 1 further scrutinizes the null result from the pooled analysis. Note that the estimated standard errors from most specifications imply that the data have 80 percent power for a "minimum detectable effect" of 8.4 percentage points (with a five percent significance level, Ioannidis et al. (2017)). While this is a large effect, it is quite plausible ${ }^{8}$

The first three estimates in the top panel rely on unadjusted local linear regressions for varying bandwidths. Only with a doubled bandwidth is the point estimate positive and significant at the 5 percent level; however, this increased precision probably comes at the

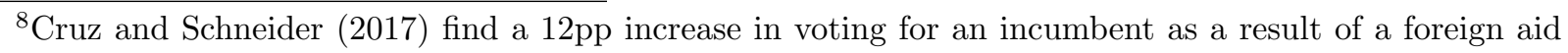
program, and Manacorda et al. (2011) find an 11-14pp increase in reported government support as the result of a larger cash transfer program.
} 


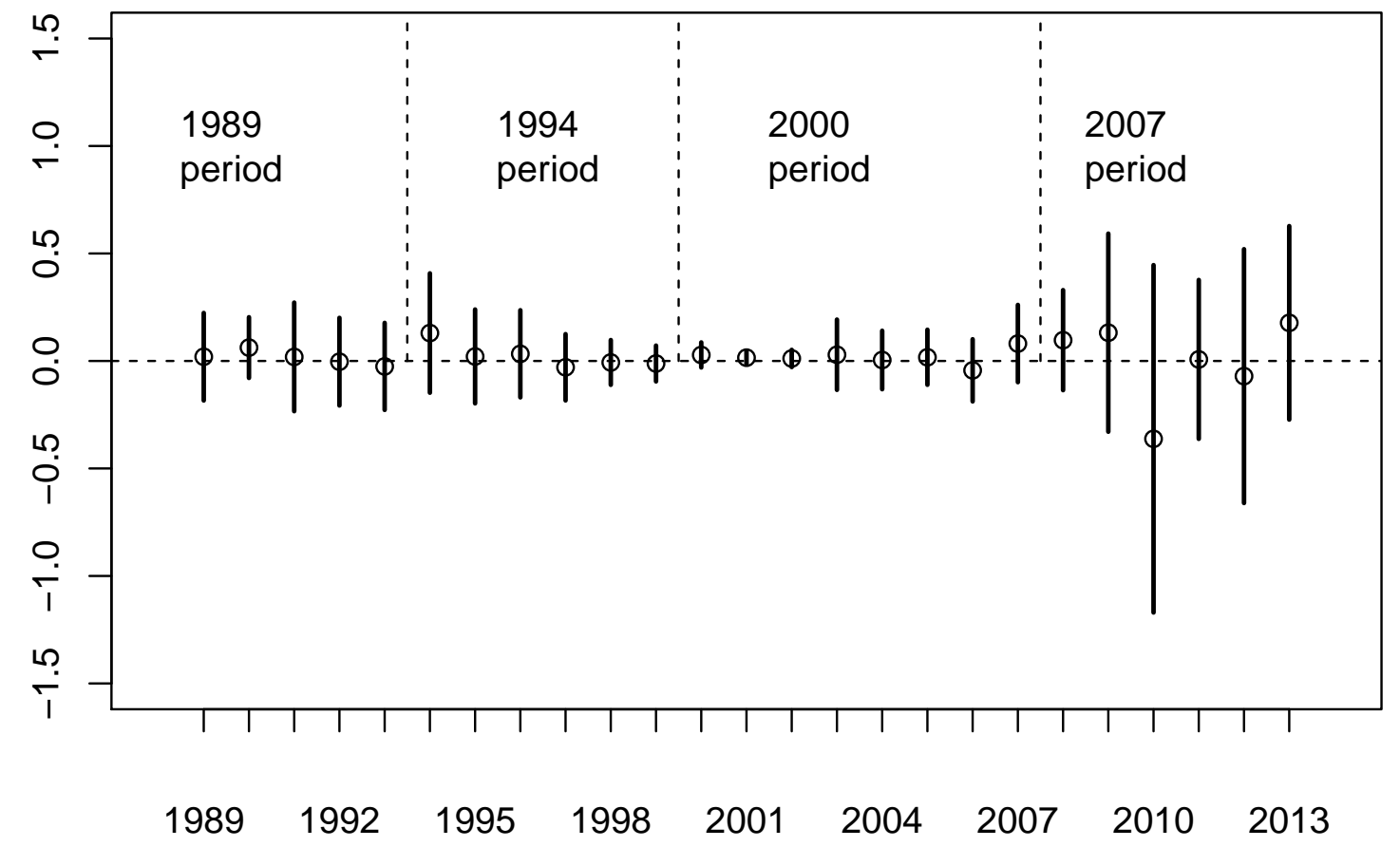

Figure 3. Year-by-year RD estimates of the impact of EU Funds on support for the EU

Note: 95 percent confidence intervals based on local linear regressions with Imbens-Kalyanaraman bandwidths and a heteroscedasticity-consistent estimator of the standard errors. Bold lines are unadjusted, while dotted lines are based on an estimator that adjusts for past EU opinion.

cost of huge bias. The next two estimates are adjusted for past attitudes and use a triangular kernel, respectively, and are also small and insignificant. An estimate based on the procedure by Calonico et al. (2014) uses a fairly small bandwidth and leads to a somewhat larger and noisier point estimate that is also insignificant. Estimates with the change from the first year to the fourth year of each period as the dependent variable are very close to zero and insignificant (see Table A4 in the appendix). Finally, the standard errors estimates for the 1994 period may suffer from bias as the F-statistics is 14 (Feir et al., 2016).9 Confidence intervals that are robust to weak identification, however, are very similar to the previous results (Table A6 in the appendix). In sum, point estimates are relatively small, and large

\footnotetext{
${ }^{9} 1989$ period: $33 ; 2000$ period: $43 ; 2007: 130$.
} 
Table $1 \quad R D$ Estimates of the impact of EU funds on support for the EU

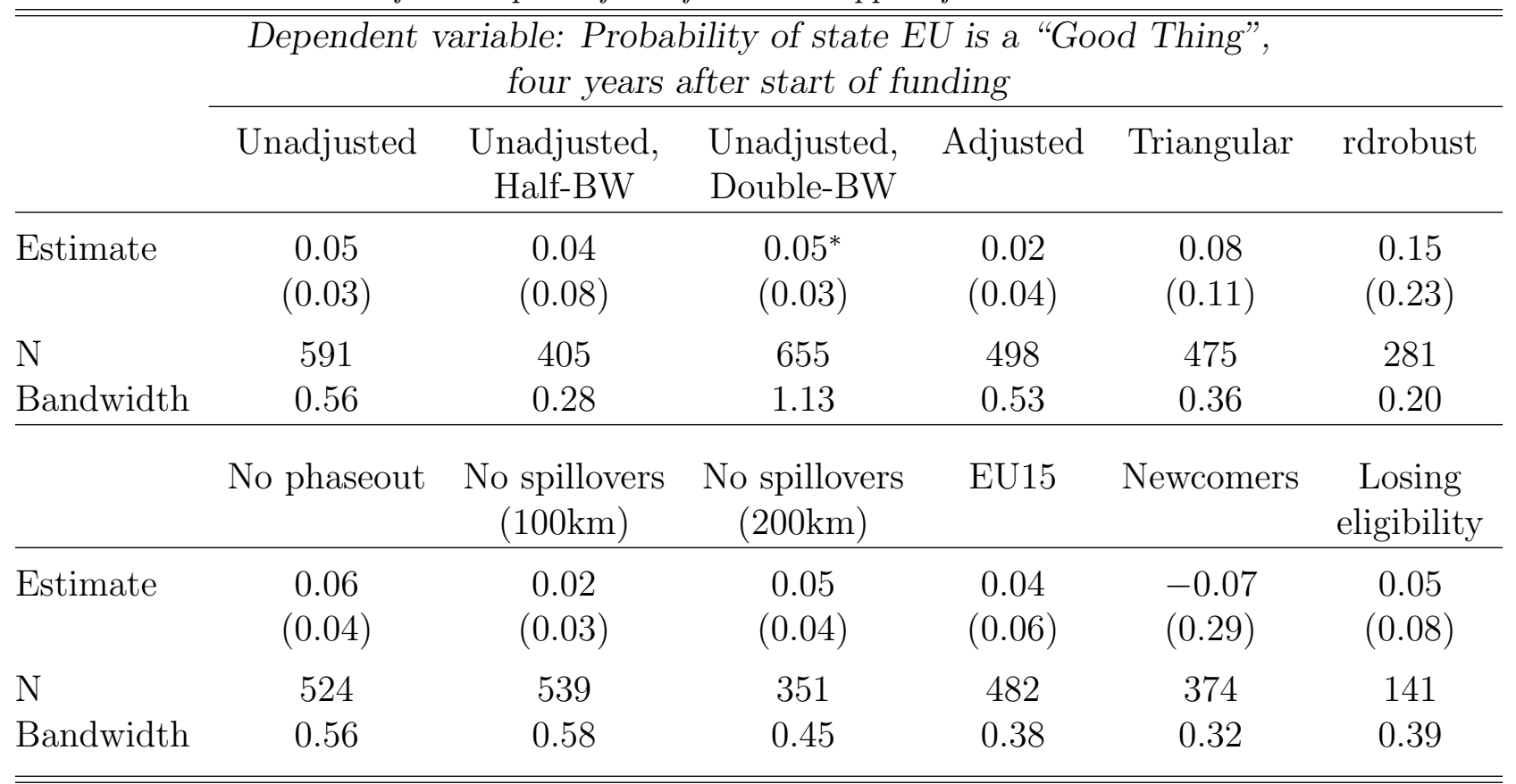

Note: ${ }^{*} \mathrm{p}<0.05$. Heteroscedasticity-consistent estimates of standard errors in parentheses. $\mathrm{N}=$ Effective number of region-periods used for estimation. For detailed explanations of the respective specifications, see main text.

effects found in other contexts can be ruled out.

The bottom panel in Table 1 explores substantively inspired robustness and heterogeneity tests. First regions that are nominally control but received "phase-out" funding after the Eastern expansion of the EU are excluded. The estimate remains insignificant. The next two columns deal with the possibility that EU funds have spillover effects. Becker et al. (2010) suggest excluding control units that are in proximity to treated units. I run two analyses and exclude control regions closer than 100 and 200 kilometers to treated ones, respectively. Estimates based on this procedure are very similar.

Estimates are also very similar when only the EU15 member states are analyzed. Finally, when only those regions that are newly funded are analyzed and when the effect of losing eligibility after a period of funding is estimated, point estimates are similarly small and insignificant. Note that these analyses have to be treated with caution as one conditions on a function of the endogenous treatment. In general, the stability of the effect estimates 
over time and across various subsamples suggests that treatment effects for regions close to the threshold are fairly homogeneous. Results are also very similar when I introduce period fixed effects, and when I use the change in public opinion as the dependent variable (Table A4 in the appendix).

\subsection{Mechanism}

In this section, I exploit Eurobarometer surveys with questions that relate specifically to the EU structural funds, to national economic evaluations as well as vote intentions to better understand my null finding.

Surveys from 1991, 1994, and 2006 contain specific questions on the EU funds (e.g., "Does the European Community have policies to support less favored regions in its member countries or not?"). While this is not on par with the data availability for my main analysis, the varying time leads can still inform whether informational effects need some time to materialize.

Figure 4 depicts pooled and separate estimates. Regardless of whether adjusted for past general EU sentiment, the effect of the structural funds on citizens' awareness of these funds is estimated to be zero ${ }^{10}$ This is even true for the survey in 2006 which asked the question at the very end of the funding period. This implies that even after projects had been funded for more than five years, citizens on average were not more aware of the EU funds in treated compared to non-treated regions. This could be one reason why there is also no effect on general EU support.

Since the activities of EU funds are disconnected from citizens' awareness of them, the economic impact of the EU funds may be misattributed to national incumbents de Vries, 2018, 95). In line with the economic voting literature, I analyze the impact of the EU funds on economic evaluations as well as support for the national incumbent. The first panel in Table 2 depicts estimates for the effect of program participation on retrospective evaluations

\footnotetext{
${ }^{10}$ The effect for 1995 is borderline significant at the 10 percent level. Exact estimates can be found in Table A7 in the appendix.
} 


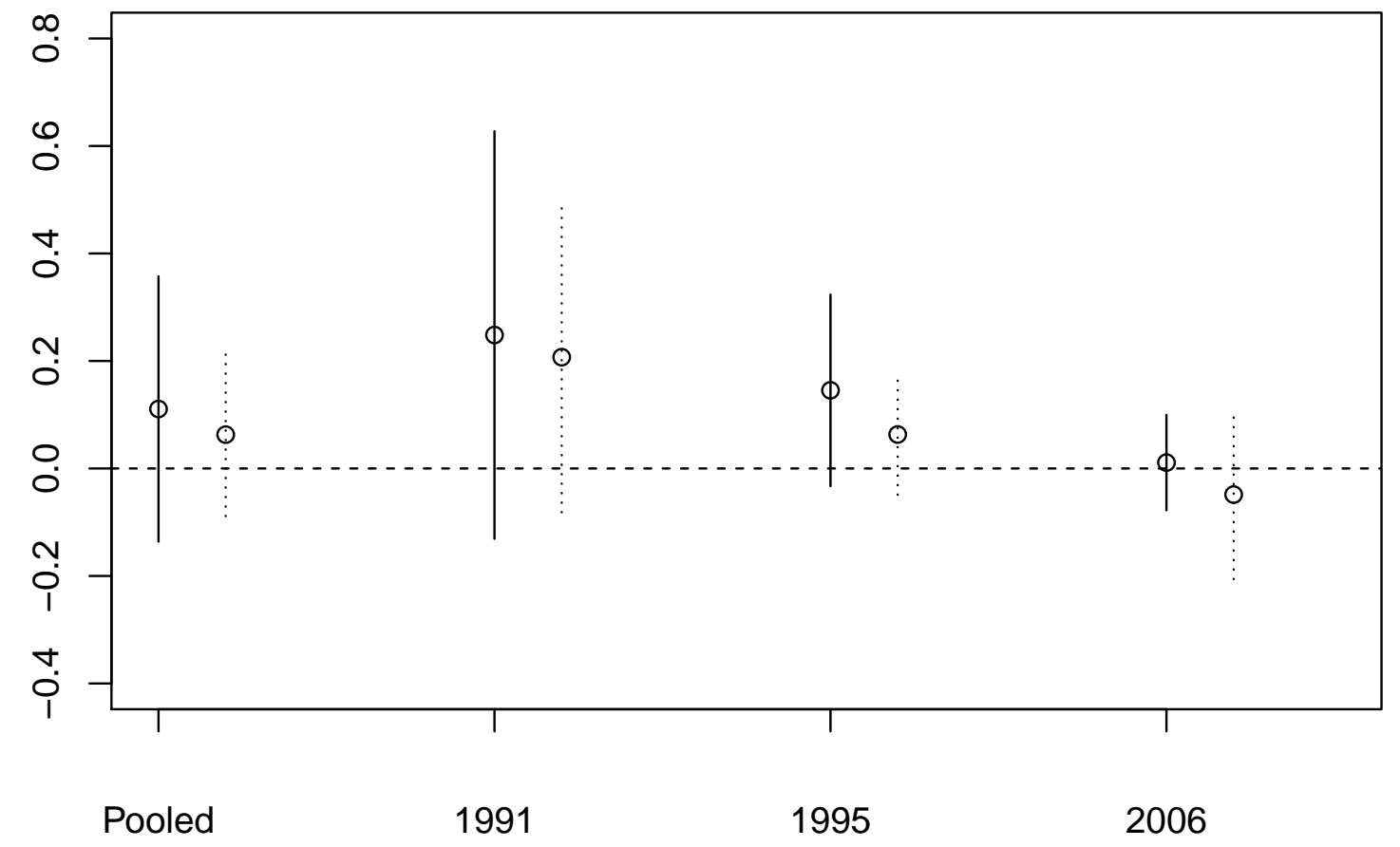

Figure 4. RD Estimates of the impact of EU funds on awareness of the policy Note: 95 percent confidence intervals based on local linear regressions with Imbens-Kalyanaraman bandwidths and a heteroscedasticity-consistent estimator of the standard errors. Bold lines are unadjusted, while dotted lines are based on an estimator that adjusts for past EU opinion.

of the general economy on a five-point scale. The estimates are quite sensitive and are insignificant in many cases. Table A7 in the online appendix with year-by-year estimates shows similar results.

Panel two of Table 2 depicts corresponding estimates where the dependent variable is the stated intention to vote for the national incumbent party. None of the estimates are statistically significant, and most estimates are very small. However, when one disaggregates by year, one sees more heterogeneous effects (Table A8 in the online appendix). Specifically, estimates for the 1989 funding period are positive throughout and statistically significant on at least the 10 percent level for 1989 and 1991. Granted, the evidence here is not very strong. 
Table 2 RD Estimates of the impact of EU funds on economic evaluations and support for incumbent

\begin{tabular}{|c|c|c|c|c|c|c|}
\hline \multicolumn{7}{|c|}{$\begin{array}{c}\text { Dependent variable: Retrospective economic evaluations, on a 1-5 scale, } \\
\text { two years after start of funding }\end{array}$} \\
\hline & Unadjusted & $\begin{array}{l}\text { Unadjusted, } \\
\text { Half-BW }\end{array}$ & $\begin{array}{l}\text { Unadjusted, } \\
\text { Double-BW }\end{array}$ & Adjusted & Triangular & rdrobust \\
\hline Estimate & $\begin{array}{l}0.16^{*} \\
(0.07)\end{array}$ & $\begin{array}{c}0.44 \\
(0.49)\end{array}$ & $\begin{array}{l}0.07^{\circ} \\
(0.04)\end{array}$ & $\begin{array}{l}0.17^{\circ} \\
(0.09)\end{array}$ & $\begin{array}{l}0.37 \\
(0.34)\end{array}$ & $\begin{array}{c}0.56 \\
(0.62)\end{array}$ \\
\hline $\mathrm{N}$ & 353 & 179 & 444 & 253 & 248 & 126 \\
\hline Bandwidth & 0.34 & 0.17 & 0.67 & 0.25 & 0.21 & 0.15 \\
\hline \multicolumn{7}{|c|}{$\begin{array}{c}\text { Dependent variable: Probability to vote for national incumbent party } \\
\text { two years after start of funding }\end{array}$} \\
\hline & Unadjusted & $\begin{array}{l}\text { Unadjusted, } \\
\text { Half-BW }\end{array}$ & $\begin{array}{l}\text { Unadjusted, } \\
\text { Double-BW }\end{array}$ & Adjusted & Triangular & rdrobust \\
\hline Estimate & $\begin{array}{l}-0.02 \\
(0.01)\end{array}$ & $\begin{array}{l}-0.04 \\
(0.03)\end{array}$ & $\begin{array}{l}-0.02 \\
(0.01)\end{array}$ & $\begin{array}{l}-0.02 \\
(0.02)\end{array}$ & $\begin{array}{l}-0.18 \\
(0.37)\end{array}$ & $\begin{array}{l}-0.33 \\
(0.66)\end{array}$ \\
\hline $\mathrm{N}$ & 451 & 325 & 476 & 338 & 241 & 163 \\
\hline Bandwidth & 0.55 & 0.28 & 1.11 & 0.35 & 0.22 & 0.15 \\
\hline
\end{tabular}

Note: ${ }^{\circ} \mathrm{p}<0.10,{ }^{*} \mathrm{p}<0.05$. Heteroscedasticity-consistent estimates of standard errors in parentheses. $\mathrm{N}=$ Effective number of region-periods used for estimation. For detailed explanations of the respective specifications, see main text.

To sum up, one reason why the funds have little effect on EU attitudes is that they have no positive impact on citizens' knowledge about them. Accordingly, the economic effects of the EU program are likely to be misattributed to other political or economic actors, although I find little evidence for this in the data.

\section{Conclusion}

The empirical evidence overwhelmingly supports the notion that the EU funds have little to no impact on what people think about European integration. Additionally, analyses over time and for various subsamples suggest that there is low heterogeneity in treatment effects, at least for regions close to the threshold. My results further suggest that actions by the EU need to explicitly activate cognitive processes in citizens that connect the impact of these 
actions to the EU if it aims to enhance its public standing.

It is instructive to analyze the development of the legal provisions of the program in this regard. The relevant document for the 1989 funding period (Council Regulation 2052/88) is merely 12 pages long and does not specify any public-relations activities with regards to the funds. In comparison, the regulation for the 2007 period, more than four times its length, explicitly prescribes that member states should address "European Union citizens and beneficiaries with the aim of highlighting the role of the [European] Community" (Council Regulation 1083/2006, Article 69). The regulation of the current 2014 funding period is even stricter (Council Regulation 1303/2013, Annex XII) ${ }^{11}$

It stands to reason that this change in the legal framework, along with the stricter requirements regarding project drafting discussed earlier, reflects learning by the Commission that its interests and the interests of member states have not been aligned. The lack of incentives for member states to communicate the program effectively could explain my empirical results. The changes in the regulation were then intended to make sure that national and local incumbents had less leeway in spending the funds in a politically opportunistic way and to ensure that the contribution by the EU is communicated appropriately. As it turns out, one does not see any consequences of these institutional reforms in the data. This could be one point for future reforms. Economic imbalances between member states are at the core of many of the EU's problems. They need to be addressed effectively and with adequate public communication.

\section{References}

Achen, C. H. and L. M. Bartels (2016). Democracy for Realists: Why Elections Do Not Produce Responsive Government. Princeton University Press.

\footnotetext{
${ }^{11}$ See also the European Parliament's PR efforts on https://what-europe-does-for-me.eu/.
} 
Bachtrögler, J., C. Hammer, W. H. Reuter, and F. Schwendinger (2017). Spotlight on the beneficiaries of eu regional funds: A new firm-level dataset.

Bargain, O., M. Dolls, C. Fuest, D. Neumann, A. Peichl, N. Pestel, and S. Siegloch (2013). Fiscal union in europe? redistributive and stabilizing effects of a european tax-benefit system and fiscal equalization mechanism. Economic Policy 28(75), 375-422.

Becker, S. O., P. H. Egger, and M. von Ehrlich (2010). Going nuts: The effect of eu structural funds on regional performance. Journal of Public Economics 94(9-10), 578-590.

Becker, S. O., P. H. Egger, and M. von Ehrlich (2013). Absorptive capacity and the growth and investment effects of regional transfers: A regression discontinuity design with heterogeneous treatment effects. American Economic Journal: Economic Policy 5(4), 29-77.

Bodenstein, T. and A. Kemmerling (2011). Ripples in a rising tide: Why some eu regions receive more structural funds than others. European Integration Online Papers 16.

Borz, G., H. Brandenburg, and C. Mendez (2018). The impact of eu cohesion policy on european identity: Results from the cohesify citizen survey.

Bouvet, F. and S. Dall'Erba (2010). European regional structural funds: How large is the influence of politics on the allocation process? JCMS: Journal of Common Market Studies $48(3), 501-528$.

Brehm, J. (1993). The phantom respondents. Ann Arbor: University of Michigan Press.

Brollo, F. and T. Nannicini (2012). Tying your enemy's hands in close races: the politics of federal transfers in brazil. American Political Science Review 106(04), 742-761.

Calonico, S., M. D. Cattaneo, and R. Titiunik (2014). Robust nonparametric confidence intervals for regression-discontinuity designs. Econometrica 82(6), 2295-2326.

Calonico, S., M. D. Cattaneo, and R. Titiunik (2015). rdrobust: An r package for robust nonparametric inference in regression-discontinuity designs. $R$ Journal 7(1), 38-51. 
Carrubba, C. J. (1997). Net financial transfers in the european union: who gets what and why? The Journal of Politics 59(2), 469-496.

Chalmers, A. W. and L. M. Dellmuth (2015). Fiscal redistribution and public support for european integration. European Union Politics 16(3), 386-407.

Charron, N. (2016). Explaining the allocation of regional structural funds: The conditional effect of governance and self-rule. European Union Politics 17(4), 638-659.

Choi, J.-y. and M.-j. Lee (2018). Relaxing conditions for local average treatment effect in fuzzy regression discontinuity. Economics Letters 173, 47-50.

Cruz, A. and C. J. Schneider (2017). Foreign aid and undeserved credit claiming. American Journal of Political Science 61(2), 396-408.

De la Cuesta, B. and K. Imai (2016). Misunderstandings about the regression discontinuity design in the study of close elections. Annual Review of Political Science 19, 375-396.

de Vries, C. E. (2018). Euroscepticism and the Future of European Integration. Oxford University Press.

Dellmuth, L. M. and A. W. Chalmers (2018). All spending is not equal: European union public spending, policy feedback and citizens' support for the eu. European Journal of Political Research 57(1), 3-23.

Dimmery, D. (2016). rdd: Regression Discontinuity Estimation. R package version 0.57.

European Commission (1997). Regional Development Studies - The Impact of Structural Policies on Economic and Social Cohesion in the Union 1989-99. Office for Official Publications of the European Commission.

European Commission (2016). Ex post evaluation of the erdf and cohesion fund 2007-13. Technical report, European Commission. 
Feir, D., T. Lemieux, and V. Marmer (2016). Weak identification in fuzzy regression discontinuity designs. Journal of Business $\& 3$ Economic Statistics 34(2), 185-196.

Foos, F. and D. Bischof (2018). Can the tabloid media create eurosceptic attitudes? a quasi-experiment on media inuence in england.

Gelman, A. and T. C. Little (1997). Poststratification into many categories using hierarchical logistic regression. Survey Methodology 23, 127-13.

Gross, M. and M. Debus (2018). Does eu regional policy increase parties' support for european integration? West European Politics 41(3), 594-614.

Hobolt, S. B. and C. E. de Vries (2016). Public support for european integration. Annual Review of Political Science 19, 413-432.

Honaker, J. and G. King (2010). What to do about missing values in time-series cross-section data. American Journal of Political Science 54(2), 561-581.

Honaker, J., G. King, M. Blackwell, et al. (2011). Amelia ii: A program for missing data. Journal of statistical software 45(7), 1-47.

Hooghe, L. and G. Marks (2005). Calculation, community and cues. European Union Politics 6(4), 419-443.

Imbens, G. and K. Kalyanaraman (2012). Optimal bandwidth choice for the regression discontinuity estimator. The Review of Economic Studies 79(3), 933-959.

Ioannidis, J. P., T. D. Stanley, and H. Doucouliagos (2017). The power of bias in economics research.

Karp, J. A., S. A. Banducci, and S. Bowler (2003). To know it is to love it? satisfaction with democracy in the european union. Comparative Political Studies 36(3), 271-292. 
Manacorda, M., E. Miguel, and A. Vigorito (2011). Government transfers and political support. American Economic Journal: Applied Economics 3(3), 1-28.

Manski, C. F. (1990). Nonparametric bounds on treatment effects. The American Economic Review 80, 319-323.

McCrary, J. (2008). Manipulation of the running variable in the regression discontinuity design: A density test. Journal of Econometrics 142(2), 698-714.

Polverari, L., D. Charles, I. Begg, and J. Bachtler (2016). The long-term effectiveness of eu cohesion policy: Assessing the achievements of the erdf, 1989-2012. In EU Cohesion Policy, pp. 11-20. Routledge.

Rubin, D. B. (1996). Multiple imputation after 18+ years. Journal of the American statistical Association 91(434), 473-489.

Schmitt, H., E. Scholz, I. Leim, and M. Moschner (2005). The mannheim eurobarometer trend file 1970-2002. Data Set Edition 2, 223. 


\section{A Further Details on Eurobarometer Surveys}

All surveys contain a regional identifier, mostly on the NUTS 2 level, that allows for matching the relevant information to respondents. I use the Mannheim Eurobarometer Trend File 1970-2002 (Schmitt et al., 2005) and all single Eurobarometers after 2002 that contained the aforementioned question on the EU. ${ }^{12}$ For each year in the 1989-2013 period, there is at least one Eurobarometer included. The median number of included surveys per year is three. Sampling is stratified across NUTS 2 units, so every region is guaranteed to be represented in every survey. The mean number of respondents per region per year is about 260; the median number is about 140, and 25 percent of region-years have less than 80 respondents.

There are a few regions for which respondents in the survey data cannot be identified as its regional coding sometimes deviates from the NUTS 2 standard. For the 1989, 1994, and 2000 funding periods, this affects twelve regions in total in France, Greece, Italy, Spain, and the UK. Some of these are extremely small and somewhat special (e.g., the French overseas departments and the Spanish regions in Northern Africa). There seems to be no underlying reason for the other regions to be missing. In total, the regional coverage is still well over 90 percent. In the 2007 period, most of these missing regions are covered. However, for unknown reasons, the data for the UK only contain the coarser NUTS 1 identifiers. This makes it impossible to compare EU opinion dynamics between the UK and the continent in detail. No other data source has similar coverage across time and space as the Eurobarometer. While this somewhat undermines the external validity of my findings, it only pertains to one out of four funding periods.

\footnotetext{
${ }^{12}$ These are Eurobarometers 58.1, 59.1, 60.1, 61, 62, 62.2, 63.4, 64.2, 65.1, 65.2, 66.1, 67.2, 69.2, 70.1, 71.1, $71.3,72.4,73.4,75.3,77.4$, and 79.5 .
} 


\section{B Further Details on the Operationalization of the Treat- ment}

I operationalize the treatment as binary. Chalmers and Dellmuth (2015) use the actual amount of spending as the treatment variable, for which there is some information available beginning in 2007. As previously explained, the Commission first unilaterally decides which regions are eligible. The amount of money a specific region receives is then the outcome of a bargaining process between the Commission and member states. Therefore, an adjustmentbased identification strategy seems moot. On the other hand, since the binary eligibility decision is causally prior to the bargaining process, a fuzzy RDD design using the amount of spending as the treatment would only work if the eligibility decision does not trigger additional action by the EU or member states which could also affect EU support. Formally, with spending variable $S, X_{r t}$ correlates with potential outcomes $Y_{r t}(s)$ due to its effect on $D_{r t}$. This is quite likely, as national or regional governments could compensate for lost EU funding or react by changing their stance on European integration.

Of equal importance is that the amount of funding is measured with huge and potentially systematic error. Bachtrögler et al. (2017) create a new database of EU-funded projects and report that the amount of spending is only measured for fifteen percent of these. Similarly, only four percent of the total project values can be attributed to the structural funds. In line with this, Polverari et al. $(2016,15)$ argue that inconsistent reporting makes the analysis of expenditures problematic. For these reasons, I concentrate on analyzing the effect of the binary program participation variable.

\section{Further Details on MRP Estimation}

For the MRP setup, I fit logistic regression models of the form 


$$
y_{i r c}=\operatorname{logit}^{-1}\left(\alpha_{r}+\alpha_{c}+\alpha_{a g e, s e x, e m p l}\right)
$$

where $i$ denotes the individual, $r$ regions, and $c$ countries for each year separately. It is assumed that $\alpha_{r}, \alpha_{c}, \alpha_{a g e, s e x, e m p l}$ are i.i.d. normal with mean zero and variance estimated from the data. This is a multilevel model where there are specific effects for regions $\left(\alpha_{r}\right)$, countries $\left(\alpha_{c}\right)$, and age-sex-employment-categories. Age categories are below 24, 24 to $34, \ldots, 64$ and above, sex is female/male, and employment is employed/unemployed.13 In a second step, the model is used to predict average support for every (region) $\times($ age, sex, employment) combination 14 and multiply these estimates with the census share of the demographic group in each region. The latter data is obtained from Eurostat. The five included variables are those for which the finest resolution is available. Taken together, this procedure generates inferences for $P\left(Y_{r t}\right)$, which can then be used in the estimation of the central quantity in equation 1.

This approach deals with random variability — due to relatively small samples per regionand systematic sample selection related to region, age, sex, and employment $t^{15}$ Since all of these variables are strongly related to sample selection and political attitudes Brehm, 1993), the post-stratification step should considerably lessen the bias introduced by survey nonresponse. Furthermore, the estimates for each group are shrunk towards the grand mean, driven by the data, which leads to lower mean-squared error. A comparison of MRP estimates and raw region-year means suggests that there is positive sample selection bias (i.e., EUfriendly respondents are more likely to participate). Often, region-years have a sample mean support of over 90 percent. The post-stratification step considerably rectifies these implausibly high estimates by 15 percentage points on average. At the same time, the

\footnotetext{
${ }^{13}$ The joint distribution of age, sex, and employment is available from 1999 onwards. For prior years, I rely only on region, age, and sex as post-stratification variables.

${ }^{14}$ Regions are completely nested in countries.

${ }^{15}$ Both the multiple imputation and the MRP procedure generate additional statistical uncertainty that could be incorporated into the estimation of the treatment effects. However, the implied standard errors are so small that this does not make a difference.
} 
shrinkage induced by the multilevel model is less than 3 percentage points. While such shrinkage in general means that outcome data from treated regions are used to estimate support in control regions, and vice versa, the resulting reduction in sampling variance should be much larger than the bias introduced by this mild shrinkage.

Unless noted otherwise, multiple imputation using the Amelia package Honaker and King, 2010; Honaker et al., 2011) is used to take care of missing values. I use self-reported left-right placement from the Eurobarometer data as a post-treatment variable to improve the imputation of the EU opinion outcome. Adjustment for this variable in the final analysis would introduce bias; however for imputation purposes, the variable contains useful information so that one achieves super-efficiency (Rubin, 1996). Overdispersion diagnostics suggest that the EM algorithm convergences to the same estimates regardless of starting values.

\section{Validity of the Design and Correlates of Funding Decisions}

Figure A1 depicts the first-stage relationship between the forcing variable (regional GDP per capita relative to the EU average) and the probability of taking part in the EU funds program across all funding periods. There is a clear discontinuity at the 75 percent threshold. This first-stage relationship yields an F-statistic of 112, which makes for a strong relationship. Further results shown in Table A1 corroborate this.

Next, I explore potential reasons for the deviations from the 75 percent threshold. I hypothesized that this may be driven by pre-existing attitudes towards the EU that are mirrored in the Eurobarometer survey. The EU commission directly finances this survey and relies on it for its decision-making. Finding such correlations does not invalidate the regression discontinuity design, as imbalances of strong confounders around the threshold are to be expected under my continuity assumption (De la Cuesta and Imai, 2016). An actual causal effect of funding decisions on attitudes measured 12 or 24 months before funding can 


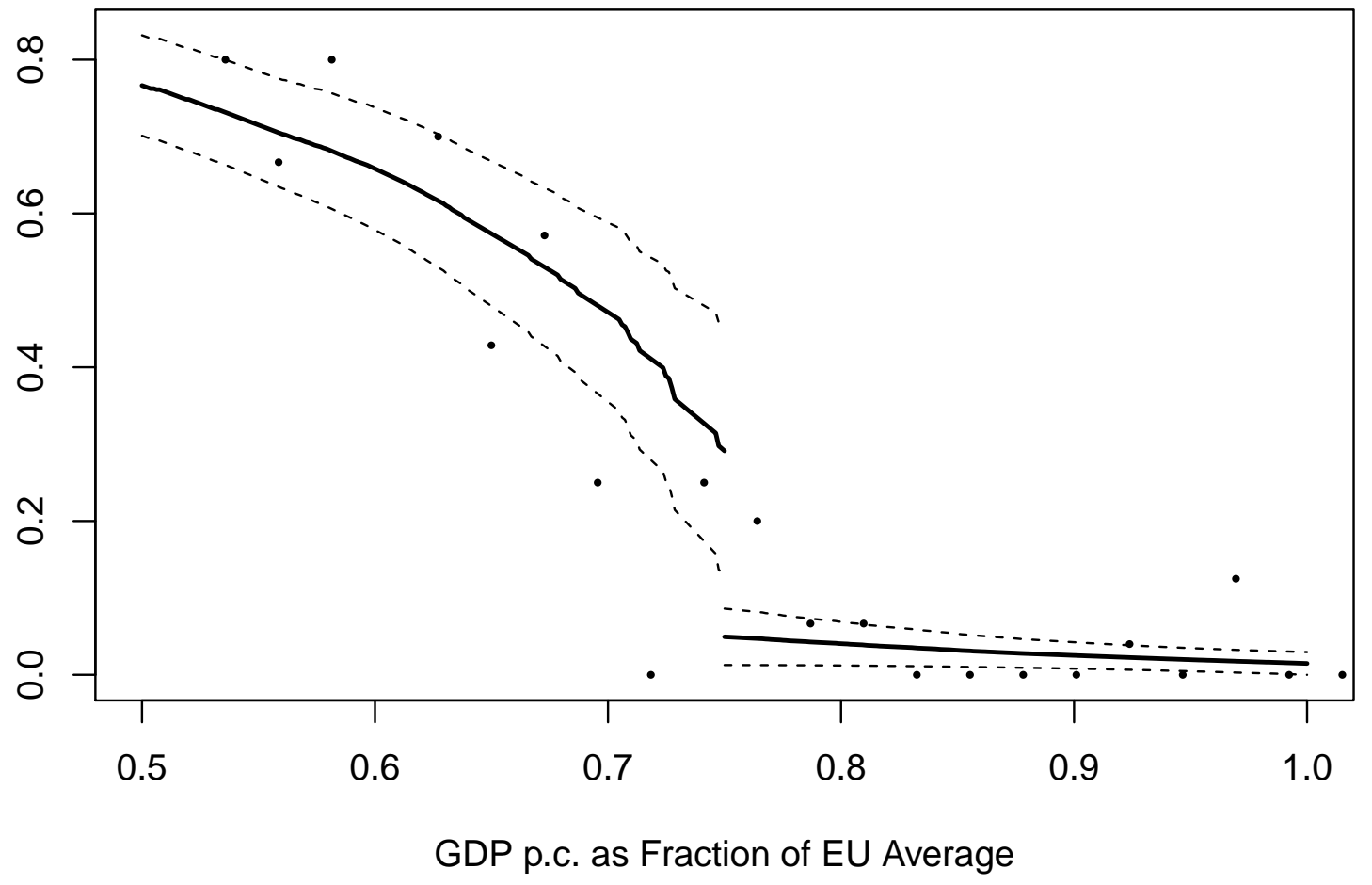

Figure A1. First stage association between program participation and GDP per capita

Note: Smoothed regression of program participation on regional GDP per capita as a fraction of the EU average and associated 95 percent confidence intervals. RD threshold is at 75 percent. Regions to the left are eligible. Based on pooled data that includes all regions in the 1989, 1994, 2000, and 2007 funding periods.

be ruled out, as the decisions by the Commission are publicly announced at most six months before the funding periods start.

Figure A2 depicts estimates from OLS regressions of average regional EU support before funding start on the treatment dummy and relative GDP per capita (I use raw data, i.e., without imputation and MRP). Regardless of whether one measures EU attitudes one or two years before funding start, there is clear evidence that it is associated with the decision to fund a region. These estimates are largely replicated using a two-stage least squares approach as reported in Table A3. The analysis suggests that conditioning on prior EU attitudes is central for getting good estimates of the effect of the funds. 


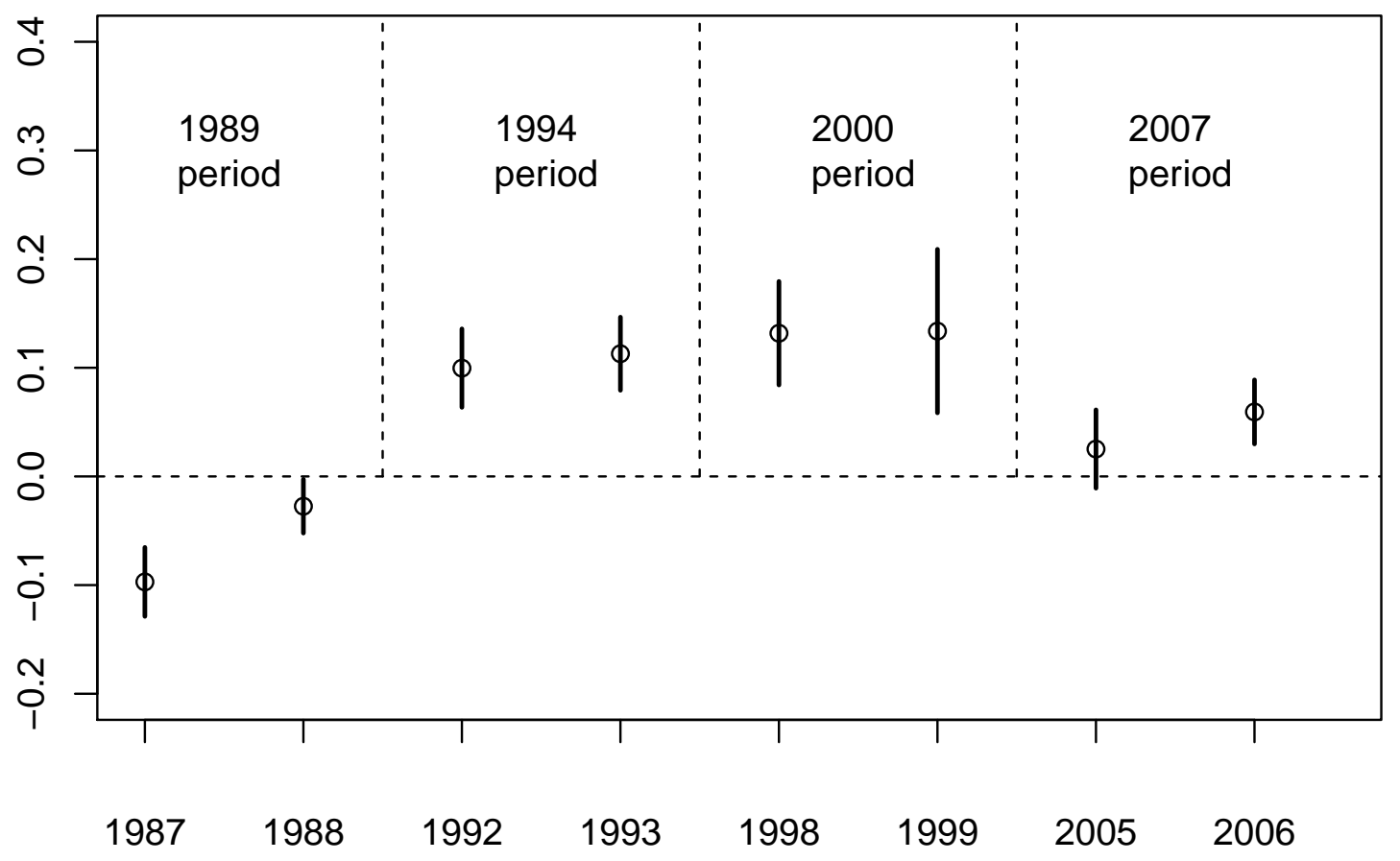

Figure A2. Association between Prior EU Attitudes and Probability of Receiving Funds Note: OLS estimates of the association between average EU attitudes one and two years before funding start and probability of receiving funding. Estimates are based on Imbens-Kalyanaraman bandwidths and a heteroscedasticity-consistent estimator of the standard errors.

Given the amount of funds involved, regions have a strong incentive to make sure they are eligible. Practically, this would involve manipulating the regional GDP statistics to make sure that it falls below the 75 percent threshold. However, as noted by Becker et al. (2013, fn. 15), in order to achieve this, the relevant statistical agency would need to predict the EUwide average GDP in advance with extreme precision. I examine this using a formal approach as proposed by McCrary (2008) and using the implementation provided by Dimmery (2016) (see Table A2). Only for the 1989 period, the test rejects the null of no differences in the density around the threshold. However, the estimated difference is actually positive - there are far more regions just above the threshold than below making it ceteris paribus harder for them to receive funds. It is possible that this is a spurious result and merely noise in the 
data. In sum, the empirical evidence appears to be consistent with the notion that national statistical agencies do not completely manipulate regional GDP to gain eligibility for the EU funds.

\section{E Estimation Results}

Table A1 First stage estimates

\begin{tabular}{lccccc}
\hline \hline & \multicolumn{3}{c}{ Dependent variable: Program Participation } & \\
\cline { 2 - 5 } & Pooled & 1989 Period & 1994 Period & 2000 Period & 2007 Period \\
\hline Estimate & $-0.33^{* * *}$ & $-0.20^{*}$ & $-0.44^{* *}$ & $-0.52^{* * *}$ & $-0.27^{* * *}$ \\
& $(0.05)$ & $(0.10)$ & $(0.15)$ & $(0.07)$ & $(0.06)$ \\
$\mathrm{N}$ & 509 & 128 & 88 & 136 & 165 \\
Bandwidth & 0.41 & 0.39 & 0.24 & 0.38 & 1.10 \\
\hline \hline
\end{tabular}

Note: ${ }^{*} \mathrm{p}<0.05,{ }^{* *} \mathrm{p}<0.01,{ }^{* * *} \mathrm{p}<0.001$. The independent variable is a dummy indicating whether a region's GDP is below the 75 percent threshold. Estimates are based on local linear regressions. Heteroscedasticity-consistent estimates of standard errors in parentheses. $\mathrm{N}=$ Effective number of region-periods used for estimation.

Table A2 Tests for sorting around the 75 percent threshold

\begin{tabular}{lcccc}
\hline \hline & 1989 Period & 1994 Period & 2000 Period & 2007 Period \\
\hline Estimate & $1.03^{* *}$ & -0.29 & -0.14 & 0.18 \\
& $(0.38)$ & $(0.33)$ & $(0.36)$ & $(0.29)$ \\
$\mathrm{N}$ & 169 & 170 & 194 & 194 \\
Bandwidth & 0.35 & 0.46 & 0.42 & 0.48 \\
\hline \hline
\end{tabular}

Note: ${ }^{* *} \mathrm{p}<0.01$. Estimates of log differences in the height of the density at the 75 percent threshold. Based on McCrary (2008). N = total number of observations. Negative estimates would imply that regional GDP per capita statistics could have been manipulated to secure EU funding. 
Table A3 Placebo estimates

\begin{tabular}{lcccccccc}
\hline \hline \multirow{2}{*}{ Dependent variable: } & A verage EU support in specified year, before actual program start \\
\cline { 2 - 9 } & 1987 & 1988 & 1992 & 1993 & 1998 & 1999 & 2005 & 2006 \\
\hline Estimate & $-0.10^{* * *}$ & $-0.03^{*}$ & $0.10^{* * *}$ & $0.11^{* * *}$ & $0.13^{* * *}$ & $0.13^{* * *}$ & 0.03 & $0.06^{* * *}$ \\
& $(0.02)$ & $(0.01)$ & $(0.02)$ & $(0.02)$ & $(0.02)$ & $(0.04)$ & $(0.02)$ & $(0.01)$ \\
$\mathrm{N}$ & 3,734 & 6,475 & 4,501 & 1,774 & 6,471 & 2,359 & 8,555 & 11,138 \\
Bandwidth & 0.09 & 0.17 & 0.11 & 0.13 & 0.18 & 0.15 & 0.24 & 0.30 \\
\hline \hline
\end{tabular}

Note: ${ }^{\circ} \mathrm{p}<0.10,{ }^{*} \mathrm{p}<0.05,{ }^{* *} \mathrm{p}<0.01,{ }^{* * *} \mathrm{p}<0.001$. The independent variable is a dummy indicating whether a region is actually eligible for funding. Unlike in the other analyses, the data here are original Eurobarometer datasets. The number of observations, therefore, refers to individual survey respondents. The first row shows OLS estimates, using the Imbens-Kalyanaraman-optimal bandwidth. These are adjusted for regional GDP per capita. Heteroscedasticity-consistent estimates of standard errors in parentheses.

Table A4 Further RD estimates of the impact of EU funds on support for the EU

\begin{tabular}{|c|c|c|c|c|c|}
\hline & \multicolumn{5}{|c|}{ Dependent variable: Probability to state EU is a "Good Thing" } \\
\hline & One-year lead & Adjusted & Two-year lead & Adjusted & Three-year lead \\
\hline Estimate & $\begin{array}{c}0.01 \\
(0.05)\end{array}$ & $\begin{array}{c}0.00 \\
(0.07)\end{array}$ & $\begin{array}{c}0.03 \\
(0.07)\end{array}$ & $\begin{array}{c}0.04 \\
(0.07)\end{array}$ & $\begin{array}{c}0.04 \\
(0.07)\end{array}$ \\
\hline $\mathrm{N}$ & 509 & 379 & 496 & 395 & 498 \\
\hline Bandwidth & 0.41 & 0.29 & 0.38 & 0.30 & 0.38 \\
\hline & Adjusted & Four-year lead & Adjusted & First Difference $t_{4}-t_{1}$ & Adjusted \\
\hline Estimate & $\begin{array}{c}0.06 \\
(0.10)\end{array}$ & $\begin{array}{c}0.05 \\
(0.03)\end{array}$ & $\begin{array}{c}0.02 \\
(0.04)\end{array}$ & $\begin{array}{c}0.02 \\
(0.05)\end{array}$ & $\begin{array}{l}-0.01 \\
(0.05)\end{array}$ \\
\hline $\mathrm{N}$ & 366 & 591 & 498 & 481 & 435 \\
\hline Bandwidth & 0.28 & 0.56 & 0.53 & 0.32 & 0.38 \\
\hline & Period FE & Adjusted & & & \\
\hline Estimate & $\begin{array}{c}0.05 \\
(0.03)\end{array}$ & $\begin{array}{c}0.01 \\
(0.04)\end{array}$ & & & \\
\hline $\mathrm{N}$ & 591 & 498 & & & \\
\hline Bandwidth & 0.56 & 0.53 & & & \\
\hline
\end{tabular}

Note: Adjusted estimates control for average EU support before the respective funding period. Heteroscedasticity-consistent estimates of standard errors in parentheses. $\mathrm{N}=$ Effective number of region-periods used for estimation. For detailed explanations of the respective specifications, see main text. 
Table A5 Year-by-year RD estimates of the impact of EU funds on support for the EU

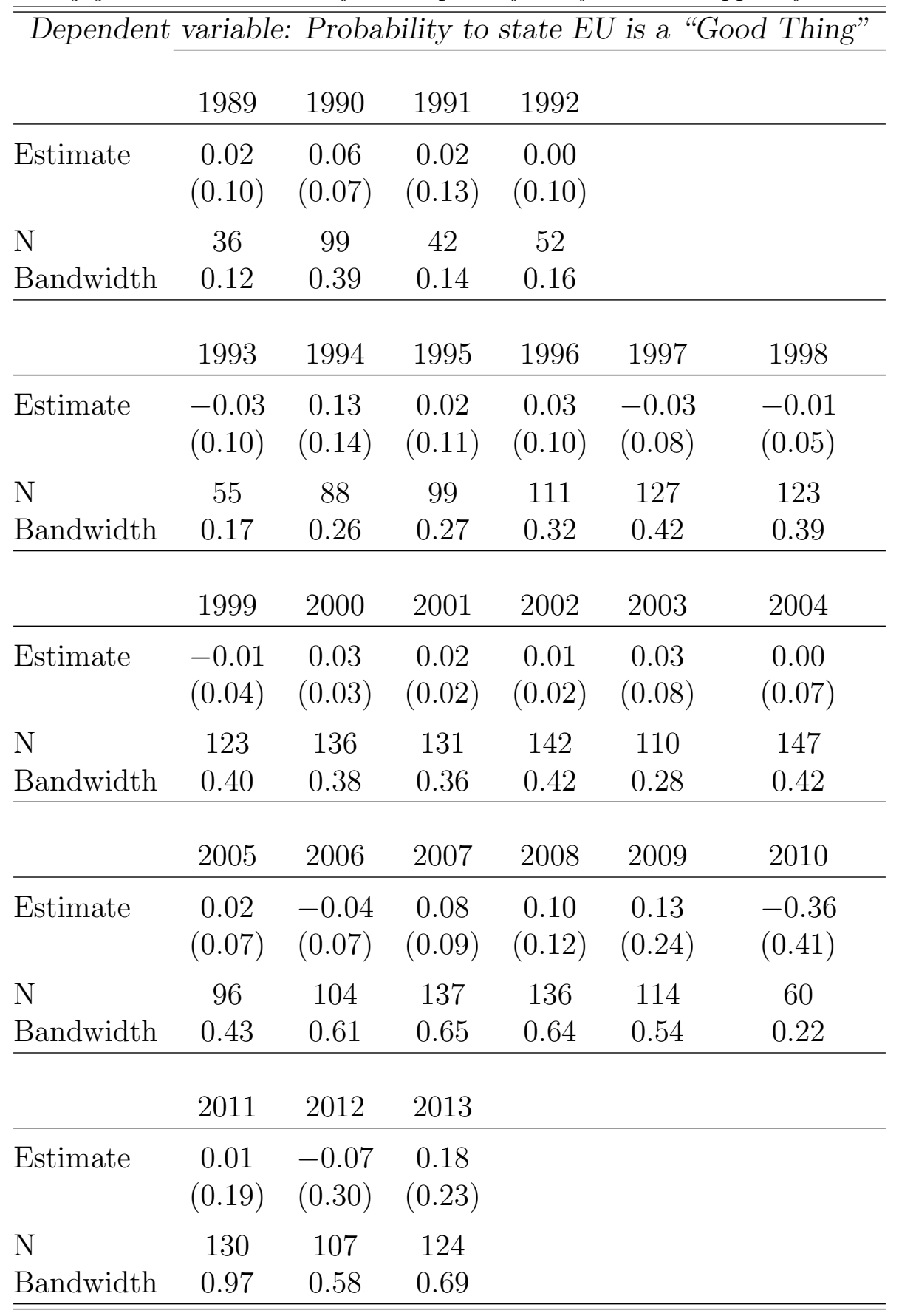

Note: Heteroscedasticity-consistent estimates of standard errors in parentheses. Estimates are adjusted throughout for average EU support before the respective funding period. Estimates for 1989, 1991, 1992, 1993, and 2010 are conservative and based on half of the Imbens-Kalyanaramanoptimal bandwidth due to numerical problems with the standard bandwidth. $\mathrm{N}=$ Effective number of region-periods used for estimation. For detailed explanations of the respective specifications, see main text. 


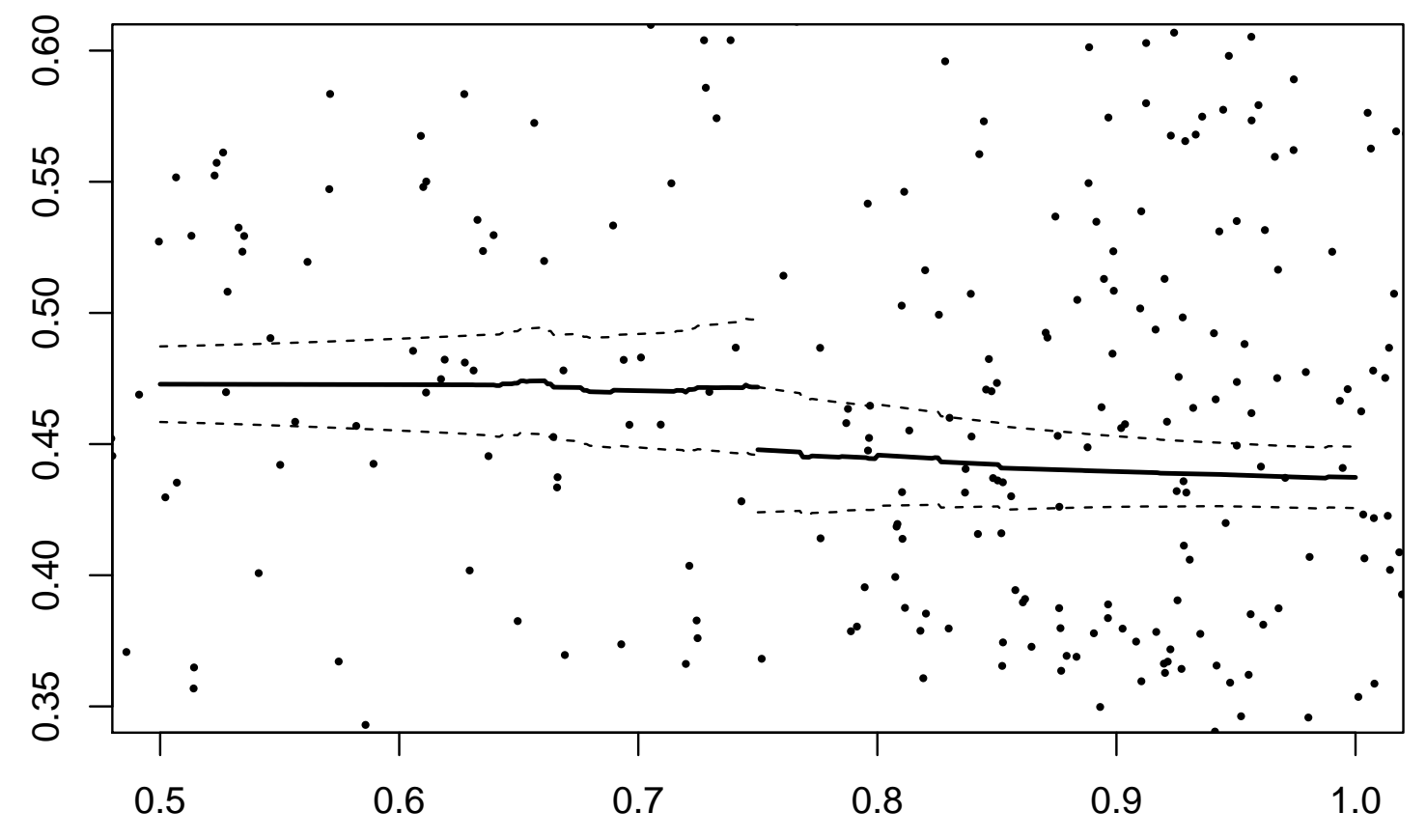

Figure A3. Reduced-form relationship between EU opinion and GDP per capita

Note: Smoothed regression of EU opinion measured four years after program start on regional GDP per capita as a fraction of the EU average and associated 95 percent confidence intervals. RD threshold is at 75 percent. Regions to the left are eligible. Based on pooled data that includes all regions in the 1989, 1994, 2000, and 2007 funding periods.

Table A6 Anderson-Rubin confidence intervals for the 1994 period

\begin{tabular}{ccc}
\hline \hline \multicolumn{3}{c}{ Dependent variable: } \\
\multicolumn{3}{c}{ Probability to state EU is a "Good Thing" } \\
\hline 1994 & 1995 & 1996 \\
\hline$(-0.05,0.67)$ & $(-0.18,0.27)$ & $(-0.17,0.26)$ \\
\hline \hline 1997 & 1998 & 1999 \\
\hline$(-0.20,0.13)$ & $(-0.12,0.10)$ & $(-0.10,0.07)$ \\
\hline \hline
\end{tabular}

Note: The independent variable is a dummy indicating whether a region's GDP is below the 75 percent threshold. Estimates are based on local linear regressions, with Imbens-Kalyanaramanoptimal bandwidths, and adjusted for regional support before program start. Anderson-Rubinbased confidence intervals are reported because the first-stage for the 1994 period is relatively weak. 
Table A7 RD estimates of the impact of EU funds on alternative outcomes

\begin{tabular}{|c|c|c|c|c|c|c|}
\hline \multicolumn{7}{|c|}{ Dependent variable: Probability to state that one is aware of the policy } \\
\hline & Pooled & Adjusted & 1991 & Adjusted & 1995 & Adjusted \\
\hline Estimate & $\begin{array}{c}0.11 \\
(0.13) \\
\end{array}$ & $\begin{array}{c}0.06 \\
(0.08) \\
\end{array}$ & $\begin{array}{c}0.25 \\
(0.19) \\
\end{array}$ & $\begin{array}{c}0.21 \\
(0.15) \\
\end{array}$ & $\begin{array}{c}0.15 \\
(0.09) \\
\end{array}$ & $\begin{array}{c}0.06 \\
(0.06) \\
\end{array}$ \\
\hline $\mathrm{N}$ & 319 & 343 & 129 & 103 & 119 & 129 \\
\hline \multirow[t]{2}{*}{ Bandwidth } & 0.31 & 0.52 & 0.44 & 0.15 & 0.32 & 0.47 \\
\hline & 2006 & Adjusted & & & & \\
\hline Estimate & $\begin{array}{c}0.01 \\
(0.05) \\
\end{array}$ & $\begin{array}{l}-0.05 \\
(0.08) \\
\end{array}$ & & & & \\
\hline $\mathrm{N}$ & 144 & 90 & & & & \\
\hline Bandwidth & 0.83 & 0.38 & & & & \\
\hline
\end{tabular}

Dependent variable: Retrospective national economic evaluations

\begin{tabular}{lcccccc} 
& Pooled & 1989 & 1990 & 1991 & 1992 & 1993 \\
\hline Estimate & $0.16^{*}$ & 0.40 & -0.69 & 0.16 & 0.25 & 0.24 \\
& $(0.07)$ & $(0.45)$ & $(0.43)$ & $(0.27)$ & $(0.42)$ & $(0.20)$ \\
\hline $\mathrm{N}$ & 353 & 118 & 60 & 128 & 122 & 51 \\
Bandwidth & 0.34 & 0.38 & 0.15 & 0.44 & 0.39 & 0.13 \\
\hline \hline & & & & & & \\
& 1994 & 1995 & 1996 & 1997 & 1998 & 1999 \\
\hline Estimate & 0.08 & 0.06 & 0.04 & 0.08 & 0.06 & 0.02 \\
& $(0.12)$ & $(0.06)$ & $(0.05)$ & $(0.05)$ & $(0.06)$ & $(0.05)$ \\
\hline $\mathrm{N}$ & 100 & 97 & 110 & 94 & 90 & 99 \\
Bandwidth & 0.30 & 0.25 & 0.29 & 0.25 & 0.24 & 0.27 \\
\hline \hline & & & & & \\
& 2000 & 2001 & 2002 & & & \\
\hline Estimate & -0.01 & 0.00 & 0.00 & & & \\
\hline $\mathrm{N}$ & $(0.05)$ & $(0.05)$ & $(0.05)$ & & & \\
Bandwidth & 0.44 & 0.49 & 0.53 & & & \\
\hline \hline
\end{tabular}

Note: ${ }^{*} \mathrm{p}<0.05$. Heteroscedasticity-consistent estimates of standard errors in parentheses. Estimates for economic evaluations 1990 and 1993 are conservative and based on half of the optimal bandwidth due to numerical problems with the standard bandwidth. $\mathrm{N}=$ Effective number of region-periods used for estimation. For detailed explanations of the respective specifications, see main text. 
Table A8 RD estimates of the impact of EU funds on alternative outcomes (ctd.)

\begin{tabular}{lcccccc}
\hline \hline \multirow{2}{*}{ Dependent } & variable: & Intention to vote for national incumbent \\
\cline { 2 - 7 } & Pooled & 1989 & 1990 & 1991 & 1992 & 1993 \\
\hline Estimate & -0.02 & $0.26^{*}$ & 0.08 & $0.11^{\circ}$ & 0.01 & -0.18 \\
& $(0.01)$ & $(0.13)$ & $(0.08)$ & $(0.06)$ & $(0.04)$ & $(0.47)$ \\
\hline $\mathrm{N}$ & 451 & 62 & 55 & 60 & 140 & 117 \\
Bandwidth & 0.56 & 0.15 & 0.14 & 0.14 & 0.60 & 0.33 \\
\hline \hline
\end{tabular}

\begin{tabular}{lcccccc} 
& 1994 & 1995 & 1996 & 1997 & 1998 & 1999 \\
\hline Estimate & 0.00 & -0.01 & 0.00 & -0.03 & 0.01 & -0.04 \\
& $(0.05)$ & $(0.03)$ & $(0.01)$ & $(0.04)$ & $(0.01)$ & $(0.04)$ \\
\hline $\mathrm{N}$ & 131 & 145 & 150 & 129 & 94 & 122 \\
Bandwidth & 0.49 & 0.42 & 0.46 & 0.35 & 0.24 & 0.34 \\
\hline \hline
\end{tabular}

\begin{tabular}{lccc} 
& 2000 & 2001 & 2002 \\
\hline Estimate & 0.01 & $(0.00)$ & 0.00 \\
& $(0.05)$ & $(0.01)$ & $(0.02)$ \\
\hline $\mathrm{N}$ & 130 & 131 & 141 \\
Bandwidth & 0.35 & 0.36 & 0.43 \\
\hline \hline
\end{tabular}

Note: ${ }^{\circ} \mathrm{p}<0.10,{ }^{*} \mathrm{p}<0.05$. Heteroscedasticity-consistent estimates of standard errors in parentheses. Estimates for 1989, 1990, and 1991 are conservative and based on half of the optimal bandwidth due to numerical problems with the standard bandwidth. $\mathrm{N}=$ Effective number of region-periods used for estimation. For detailed explanations of the respective specifications, see main text. 